\title{
Anabases
}

ANABASES Traditions et réceptions de l'Antiquité

12 | 2010

Varia

\section{Emily BARAGWANATH, Motivation and Narrative in \\ Herodotus}

Pascal Payen

\section{(2) OpenEdition}

Journals

Édition électronique

URL : http://journals.openedition.org/anabases/931

DOI : 10.4000/anabases.931

ISSN : 2256-9421

\section{Éditeur}

E.R.A.S.M.E.

\section{Édition imprimée}

Date de publication : 1 octobre 2010

Pagination : 241-242

ISSN : 1774-4296

\section{Référence électronique}

Pascal Payen, «Emily baragwanath, Motivation and Narrative in Herodotus », Anabases [En ligne], 12

2010, mis en ligne le 01 juillet 2011, consulté le 22 septembre 2020. URL : http://

journals.openedition.org/anabases/931 ; DOI : https://doi.org/10.4000/anabases.931

Ce document a été généré automatiquement le 22 septembre 2020.

(c) Anabases 


\title{
Emily BARAGWANATH, Motivation and Narrative in Herodotus
}

\author{
Pascal Payen
}

\section{RÉFÉRENCE}

Emily BARAGWANATH, Motivation and Narrative in Herodotus, Oxford, Oxford University

Press, 2008, XII-374 p.

43 euros / ISBN 978-0-19-923129-4.

1 Hérodote, parce qu'il aurait été le premier historien, le "père de l'histoire ", selon l'expression de Cicéron, aurait aussi fait preuve de naïveté, étant précisément le premier, œuvrant sans le lest d'une tradition qui lui aurait légué les règles du métier. C'est le même Cicéron qui est responsable de ce double jugement, en ajoutant que l'œuvre d'Hérodote est remplie d'innumerabiles fabulae (De legibus, I, 1, 5). La naïveté serait d'abord enracinée dans l'art du récit, dans la fable. Le seul moyen de revenir sur un des lieux communs les plus enracinés touchant la tradition historiographique est d'analyser la sophistication des récits, des figures et des intrigues, selon le mot consacré, mis en place par Hérodote. Le livre d'Emily Baragwanath se lance dans l'aventure tentée par beaucoup d'autres savants avant elle, depuis Hauvette, Jacoby, Immerwahr, Fornara, Erbse, Nenci, Hartog, Thomas, Munson, mais elle a retenu à la fois un thème et un outil pour l'accompagner : quelles sont, d'une part, les motivations qui animent les acteurs de l'histoire? De quelle nature, d'autre part, est le dialogue qui s'instaure ou, mieux, qu'instaure Hérodote avec ses lecteurs? De la sorte, l'hypothèse est que les récits d'Hérodote, s'il n'est pas le naïf qu'une large tradition veut reconnaitre, sont au contraire porteurs de toutes les difficultés de l'entreprise historique et des grandes questions qu'elle pose. Quel choix opère l'historien parmi «les événements qui surviennent du fait des hommes (ta genomena ex anthrôpôn)»? Dans quels contextes se situe cet acte d'écriture ? À quel public s'adresse l'historien ? Quelles significations s'attachent à la conservation du passé et à ses liens avec le 
présent dans les sociétés grecques où vit Hérodote? Quelles relations entretient l' Enquête avec les traditions narratives qui la précèdent et avec celles qu'elle suscite ensuite? Or Hérodote, en présentant à ses lecteurs plusieurs versions d'un même événement (le fameux "double éclairage»), ou en indiquant pour quelle raison il retient telle version plutôt que telle autre - ainsi à propos du règne de Cyrus, le fondateur de l'Empire perse (I, 95) -, conduit ses lecteurs à s'interroger sur la connaissance même du passé, sa constitution, son sens. On comprend ainsi que l'auteur de ce livre ait principalement recours à la théorie de «l'acte de lecture » de Wolfgang Iser (p. 22-26). On s'étonnera toutefois que les travaux de Hans Robert Jauss sur l'esthétique de la réception ne soient pas mentionnés (sauf une brève allusion, p. 23, note 69), alors qu'ils sont proches de ceux d'Iser et paraissent affleurer en plusieurs endroits dans le livre. E. Baragwanath se situe à l'opposé d'une approche formelle ou formaliste des récits; elle réaffirme l'historicité de toute œuvre historique, née avant tout de son présent et des interprétations qu'elle peut susciter. C'est pourquoi on aurait souhaité qu'il soit davantage tenu compte du moment où Hérodote a voyagé, circulé, écrit. Est-ce avant la guerre du Péloponnèse ? Est-ce plutôt dans la décennie 420 ? En fait, l'élaboration de l'œuvre s'est étendue sur deux ou trois décennies, pendant lesquelles la place d'Athènes, l'accroissement de son « empire », le développement de la literacy, l'importance des sophistes et de nouveaux savoirs, dont témoigne par exemple le traité hippocratique Airs, eaux, lieux (ca 430), ont exercé des influences profondes et multiples sur la prose historique, au sein d'aires culturelles qui ne se limitent pas au domaine athénien. Le lecteur historien regrette parfois un défaut de mise en contexte.

2 Mais ce qu'il retient davantage est la grande finesse des analyses, sans cesse appuyées sur la lettre même des textes, dans la langue originale, et toujours parfaitement au fait des interprétations récentes les plus judicieuses. Il est impossible de restituer ici la teneur des enchaînements qui s'attachent à reconstituer les " motivations » des acteurs de l'histoire, au long des neuf chapitres. Avec beaucoup de justesse, le chapitre 1 commence par rappeler qu'un des plus farouches adversaires de la thèse d'une supposée «naïveté » d'Hérodote est Plutarque, qui voit bien plutôt, dans sa manière de rapporter les événements du passé et les intentions des hommes, beaucoup de " malignité ». Plutarque parie sur l'intelligence d'Hérodote. En réagissant de manière vigoureuse à ses prétendues attaques contre les Thébains, les Argiens, les Corinthiens ou les Thessaliens, il montre que la figure du destinataire, du lecteur et donc la réception de l'œuvre sont inscrites dans l'œuvre elle-même. Le chapitre 2 revient, de manière plus classique, sur les rapports qu'entretient Hérodote avec l'héritage homérique. Au fil des études, l'auteur montre que, dans l'analyse d'Hérodote, l'écart est permanent entre les intentions humaines et le résultat de l'action. Les figures de Léonidas (chapitre 3), de Maiandrios et de Polycrate (chapitre 4), de Thémistocle (chapitre 9) et de Xerxès (chapitre 8), mais aussi des Alcméonides (chapitre 5) illustrent la complexité des interprétations que suggère l'enquêteur, reflet à la fois de la diversité des sources qu'il connaît parfaitement et de la pluralité des « lectures » que son public est capable de proposer. L'Enquête que dessine E. Baragwanath est un objet souple qui appelle l'échange avec ses lecteurs, non que cette œuvre laisse hors du champ de l'interprétation toute prétention à la vérité, mais en ce que son auteur a conscience que la vérité historique résulte d'une reconstruction des motivations humaines à travers la diversité des configurations narratives, imaginées et proposées dans un contexte précis et réactualisées par la chaîne de ses lecteurs. 


\section{AUTEURS}

PASCAL PAYEN

Université de Toulouse (UTM)

payen@univ-tlse2.fr 